\title{
GATA-4 promotes the differentiation of P19 cells into cardiac myocytes
}

\author{
DE-LIANG HU ${ }^{1 *}$, FU-KUN CHEN $^{1 *}$, YAO-QIU LIU ${ }^{1}$, YAN-HUI SHENG $^{1}$, RONG YANG $^{1}$, \\ XIANG-QING KONG ${ }^{1}$, KE-JIANG CAO ${ }^{1}$, HAI-TAO GU ${ }^{2}$ and LING-MEI QIAN ${ }^{1}$ \\ ${ }^{1}$ Department of Cardiology, First Affiliated Hospital of Nanjing Medical University, 210029 Nanjing; \\ ${ }^{2}$ Department of Cardiothoracic Surgery, Nanjing Children's Hospital of Nanjing Medical University, \\ 210008 Nanjing, P.R. China
}

Received April 13,2010; Accepted May 21, 2010

DOI: 10.3892/ijmm_00000474

\begin{abstract}
The aim of this study was to investigate the effects of GATA-4 on the differentiation of P19 cells into cardiomyocytes and to examine the relationship between GATA-4 and cardiomyocytes. We constructed vectors to overexpress and silence GATA-4. These vectors, as well as empty ones were transfected into P19 cells. Subsequently, reverse transcriptase-polymerase chain reaction (RT-PCR) and Western blot analysis were performed. The morphology of P19 cells during differentiation was observed using an inverted microscope. Total RNA was extracted from P19 cells. We used real-time PCR to evaluate the expression levels of 6 genes: GATA-4, GATA- 6 , transthyretin $(T T R), \alpha$-fetoprotein $(A F P), N k x 2.5$, and $\alpha$-myosin heavy chain $(\alpha-M H C)$. The gene expression pattern of these 6 genes is graphically shown for each group. The GATA-4 mRNA level in cells overexpressing GATA-4 was notably higher than that in the controls, whereas the levels in the controls were notably higher than those in the GATA-4-silenced P19 cells. The cell lines overexpressing GATA-4 expressed higher levels of $N k x 2.5$ and $\alpha-M H C$ than the controls. However, the controls expressed higher levels of AFP, GATA-6 and TTR than the cells overexpressing GATA-4. The RNAi group expressed lower levels of TTR, $N k x 2.5$, and $\alpha-M H C$ than the controls, but there were no differences in the RNAi group and the controls with regard to the expression levels of $A F P$ and GATA-6. The gene expression pattern in the cells over-
\end{abstract}

Correspondence to: Dr Ling-mei Qian, Department of Cardiology, First Affiliated Hospital of Nanjing Medical University, 210029 Nanjing, P.R. China

E-mail: lmqian@njmu.edu.cn

Dr Hai-tao Gu, Department of Cardiothoracic Surgery, Nanjing Children's Hospital of Nanjing Medical University, 210008 Nanjing, P.R. China

E-mail: guhaitao@hotmail.com

${ }^{*}$ Contributed equally

Key words: GATA-4, Nkx2.5, cardiac myocytes, differentiation, P19 cells expressing GATA-4 was biased toward the $N k \times 2.5$ and $\alpha$ $M H C$. On the other hand, the gene expression pattern in GATA-4-silenced cells and the controls was biased toward the TTR and AFP. The overexpression of GATA-4 enhances the differentiation of P19 cells into cardiac myocytes, whereas its down-regulation suppresses this trend.

\section{Introduction}

In higher vertebrates, cardiogenesis is a complex process that begins during the early stages of embryogenesis and involves the commitment of anterior lateral plate mesoderm cells to the cardiogenic lineage. These committed precursors subsequently differentiate into cardiomyocytes, whose proliferation is mainly responsible for heart development (1). The delicate balance between cell differentiation, proliferation, and apoptosis is crucial for proper organogenesis. Understanding the transcriptional and signaling programs that specify the cardiomyocyte fate from uncommitted progenitors, may provide important clues on the impact of cellular strategies for treating failing or infarcted heart tissue. GATA factors are comprised of a small family of highly conserved zinc finger transcription factors that play critical roles in the development of the cardiovascular, hematopoietic, digestive, and reproductive systems (2). GATA-1, GATA-2, and GATA-3 are preferentially expressed in hematopoietic cells and regulate the proliferation and differentiation of blood cells during hematopoiesis (3). GATA-4, GATA-5, and GATA-6 are predominantly expressed during cardiogenesis, in addition to other sites. The DNA-binding domains of GATA-4, GATA-5, and GATA-6 are approximately $85 \%$ similar at the protein level. During early cardiac development, GATA-4 expression is confined to the cardiac crescent, whereas later, transcripts are detected throughout the myocardium and endocardium $(4,5)$. The null mutation of GATA-4 results in the abnormal ventral folding of the embryo, failure to form a single ventral heart tube, and lethality by embryonic day (E) $10.5(6,7)$. In humans, mutations in GATA-4 result in congenital cardiomyopathies, including valve and septal defects $(8,9)$. Both conditional knockout mice lacking GATA-4 in specific cardiomyocytes, as well as transgenic mice expressing only $30 \%$ of the normal levels of GATA-4 in the heart, display atrioventricular 
canal defects and a hypoplastic ventricular myocardium. Ventricular hypoplasia is thought to be associated with defects in cardiac morphogenesis and cardiomyocyte proliferation $(10,11)$. However, the genetic programs under GATA-4 control are not well understood. P19 cells, which are isolated from an experimental embryo-derived teratocarcinoma in mice, are multipotent and can differentiate into the cell types of all 3 germ layers. Due to their ability to form cardiomyocytes, P19 cells have been used to understand the role of cardiac-specific transcription factors and upstream signaling pathways in cardiac cell differentiation (12). We constructed vectors that overexpressed GATA-4 and silenced RNA interference. We investigated the effects of GATA-4 on myocardial cell differentiation by evaluating the expression levels of GATA-4, GATA-6, transthyretin (TTR), $\alpha$-fetoprotein $(A F P), \mathrm{Nkx} 2.5$ and $\alpha$-myosin heavy chain $(\alpha-M H C)$ and thus created a chart of the expression patterns of these 6 genes.

\section{Materials and methods}

P19 cell culture and the induction of differentiation. P19 cells were cultivated as aggregates from days 0 to 6 in the presence of $1 \% \alpha$-minimal essential medium containing $10 \%$ fetal bovine serum and $1 \% \mathrm{Me}_{2} \mathrm{SO}$ (DMSO) in bacteriological dishes in a $5 \% \mathrm{CO}_{2}$ atmosphere at $37^{\circ} \mathrm{C}$. The medium was replaced every 2 days thereafter. Some cell aggregates were harvested on day 5 of differentiation. On day 6 , the other cell aggregates were transferred to cell culture flasks. The morphological changes in the P19 cells were examined under an inverted microscope (Nikon, Japan) equipped with phasecontrast objectives and a digital camera (Nikon).

Establishment of GATA-4-expressing transformants. The coding sequence of GATA-4 was subcloned into the KpnI and $X b \alpha I$ sites of a pcDNA 3.1/myc-His A expression vector by using the oligonucleotides 5'-AGGGGTACCCGCGGTG ATTATGTCCCCATGACTGTCA-3' and 5'-GCTCTAGAC CATGTACCAAAGCCTGGCCATGGCCGCCA-3' to generate a plasmid expressing the GATA-4-6X-His fusion protein. Expression vectors carrying the GATA-4 coding sequence as well as empty ones, were transfected into P19 cells. Two days after transfection, neomycin (G418) was added to the medium $(600 \mu \mathrm{g} / \mathrm{ml})$ in order to select transfected cells. Drug-resistant cells began to form small colonies 2 weeks after the addition of G418. Individual colonies were isolated and propagated, and the GATA-4-6XHis fusion protein was identified by Western blotting with an anti-GATA-4-6X-His antibody (Genetex, USA). The colonies expressing the highest levels of GATA-4 were selected for cell differentiation studies. The resulting plasmids were confirmed by sequencing.

Construction of GATA-4 short interference RNA expression plasmids. Three conserved cDNA fragments within the coding region of mouse GATA-4 were identified using the basic local alignment homology search tool. Three pairs of reverse complementary oligonucleotides were designed and synthesized, and each pair contained a loop sequence (5'-TT CAAGAGA-3'), an RNA Pol III terminator (5'-TTTTTT-3'), and $5^{\prime}$ 'single-stranded overhangs for ligation into BbsI- and
BamHI-digested pGPU6/GFP/Neo vectors. These oligonucleotides were annealed and inserted into the short interference RNA (siRNA) expression vectors. The sequences of the cDNA fragments (sense strands) were i) 5'-GCCTCTAC ATGAAGCTCCATG-3', ii) 5'-GCTCCATGTCCCAGA CATTCA-3', and iii) 5'-GCTATGCATCTCCTGT CACTC-3'. These fragments were used to create the vectors pGPU6shGATA4-1491, pGPU6-shGATA4-1743 and pGPU6shGATA4-1830, respectively. An insert-free pGPU6 vector served as the negative control. An insert control designed to target the GAPDH mRNA was used as the positive control (Ambion).

RNA interference. Five pGPU6/GFP/Neo vectors, including a negative and a positive control, were transfected into P19 cells, which were then grown in 6-well culture plates containing complete culture medium. A lipopolysaccharide-free vector ( $2 \mathrm{mg} /$ well) was used for each transfection. At $48 \mathrm{~h}$ after transfection, cells and supernatants were collected for real-time polymerase chain reaction (PCR) detection.

Western blotting. Total proteins were isolated from cultured cells, separated on a $7.5 \%$ gel by sodium dodecyl sulfate-polyacrylamide gel electrophoresis, and transferred onto polyvinylidene difluoride membranes. These membranes were incubated with a mouse anti-GATA-4-6X His antibody (Genetex) and goat anti-mouse immunoglobulin G-horseradish peroxidase conjugate (Amersham, UK). Immunoreactive proteins were detected by enhanced chemiluminescence (Amersham).

Total RNA isolation and real-time qRT-PCR. Total RNA was isolated from cultured P19 cells using the TRIzol method (Invitrogen). Single-strand cDNA was synthesized as follows: The reverse transcription mixture contained $2 \mu \mathrm{g}$ total RNA, $2 \mu 1$ oligo d(T) primer, $4 \mu 15 \mathrm{X}$ MMLV buffer, $1 \mu 1 \mathrm{dNTP}$ mix (concentration, $10 \mathrm{mM}$ ), $0.5 \mu \mathrm{l}$ RNasin (40 U/ $\mu \mathrm{l}), 1 \mu 1 \mathrm{MMLV}$ reverse transcriptase (200 U/ $\mu \mathrm{l}$; Promega, USA), and $11.5 \mu \mathrm{l}$ sterile $\mathrm{H}_{2} \mathrm{O}$ in a total volume of $20 \mu \mathrm{l}$. The reaction was carried out at $42^{\circ} \mathrm{C}$ for $1 \mathrm{~h}$, followed by heat inactivation at $95^{\circ} \mathrm{C}$ for $10 \mathrm{~min}$. For real-time PCR, $2 \mu \mathrm{l} \mathrm{cDNA} \mathrm{(40} \mathrm{ng)} \mathrm{were} \mathrm{added} \mathrm{to}$ $23 \mu 1$ of a master mix containing $1 \mathrm{U}$ SYBR-Green (Applied Biosystems, Foster City, CA, USA) and $300 \mathrm{nM}$ reverse and forward primers. cDNA was amplified for 40 cycles with an Applied Biosystems 7300 real-time PCR system (Applied Biosystems). The primer sequences used are listed in Table I. The PCR product level was calculated from the threshold cycle, the amplification cycle at which the emission intensity of the product rises above a set threshold level.

Statistical analysis. The results are expressed as mean \pm SD except that the results in Table II are expressed as mean. Data were analyzed using one-way analysis of variance and $\mathrm{t}$ - or $\mathrm{t}$-tests making corrections for multiple comparisons, as appropriate.

\section{Results}

Stable cell line overexpressing GATA-4. The P19 cell line which stably transfected with a GATA-4 plasmid was 
Table I. Primer sequences used.

\begin{tabular}{|c|c|c|c|}
\hline Gene name & Product size $(\mathrm{bp})$ & Reverse and forward primer $\left(5^{\prime}-3^{\prime}\right)$ & $\mathrm{Ta}\left({ }^{\circ} \mathrm{C}\right)$ \\
\hline GATA-4 & 212 & $\begin{array}{l}\text { R: TGCTGTGCCCATAGTGAGATGAC } \\
\text { F: GAAAACGGAAGCCCAAGAACC }\end{array}$ & 61 \\
\hline GATA-6 & 302 & $\begin{array}{l}\text { R: CTCTTGGTAGCACCAGCTCA } \\
\text { F: GCAATGCATGCGGTCTCTAC }\end{array}$ & 55 \\
\hline$T T R$ & 254 & $\begin{array}{l}\text { R: GGCTGAGTCTCTCAATTC } \\
\text { F: CTCACCACAGATGAGAAG }\end{array}$ & 60 \\
\hline$A F P$ & 238 & $\begin{array}{l}\text { R: AGGCTTTTGCTTCACCAG } \\
\text { F: TCGTATTCCAACAGGAGG }\end{array}$ & 55 \\
\hline$N k x 2.5$ & 215 & $\begin{array}{l}\text { R: CCGGTCCTAGTGTGGA } \\
\text { F: AGCAACTTCGTGAACTTTG }\end{array}$ & 57 \\
\hline$\alpha-M H C$ & 143 & $\begin{array}{l}\text { R: CTTTCGCTCGTTGGGA } \\
\text { F: ACCGTGGACTACAACAT }\end{array}$ & 52 \\
\hline GAPDH & 251 & $\begin{array}{l}\text { R: GCCAGTAGAGGCAGGGATGATGTTC } \\
\text { F: CCATGTTCGTCATGGGTGTGAACCA }\end{array}$ & 60 \\
\hline
\end{tabular}

$\mathrm{R}$, reverse primer; $\mathrm{F}$, forward primer; Ta, annealing temperature.

Table II. Expression level of marker genes in 5-day-old EBs formed in different groups.

\begin{tabular}{|c|c|c|c|c|c|}
\hline \multirow[b]{2}{*}{ Expression region } & \multirow[b]{2}{*}{ Gene } & \multicolumn{4}{|c|}{ Relative expression (ratio to maximum) } \\
\hline & & 1 & 2 & 3 & 4 \\
\hline \multirow[t]{2}{*}{$\begin{array}{l}\text { Endoderm } \\
\text { and mesoderm }\end{array}$} & GATA-4/GAPDH & $\begin{array}{c}1.214 \mathrm{E}+00 \\
(0.11)\end{array}$ & $\begin{array}{l}9.157 \mathrm{E}-01 \\
(0.09)\end{array}$ & $\begin{array}{c}1.060 \mathrm{E}+01 \\
(1)\end{array}$ & $\begin{array}{c}8.173 \mathrm{E}-02 \\
(0.01)\end{array}$ \\
\hline & GATA-6/GAPDH & $\begin{array}{c}4.343 \mathrm{E}+00 \\
\text { (1) }\end{array}$ & $\begin{array}{c}4.300 \mathrm{E}+00 \\
(0.99)\end{array}$ & $\begin{array}{c}2.346 \mathrm{E}+00 \\
(0.54)\end{array}$ & $\begin{array}{l}4.001 \mathrm{E}+00 \\
\quad(0.92)\end{array}$ \\
\hline \multirow{2}{*}{$\begin{array}{l}\text { Endoderm } \\
\text { (hepatogenesis, } \\
\text { visceral yolk sac) }\end{array}$} & TTR/GAPDH & $\begin{array}{c}2.160 \mathrm{E}+00 \\
\text { (1) }\end{array}$ & $\begin{array}{c}2.085 \mathrm{E}+00 \\
(0.97)\end{array}$ & $\begin{array}{c}1.409 \mathrm{E}+00 \\
(0.65)\end{array}$ & $\begin{array}{c}9.739 \mathrm{E}-01 \\
\quad(0.45)\end{array}$ \\
\hline & AFP/GAPDH & $\begin{array}{c}1.651 \mathrm{E}+00 \\
(0.93)\end{array}$ & $\begin{array}{c}1.774 \mathrm{E}+00 \\
\text { (1) }\end{array}$ & $\begin{array}{l}7.977 \mathrm{E}-01 \\
(0.44)\end{array}$ & $\begin{array}{c}1.546 \mathrm{E}+00 \\
(0.87)\end{array}$ \\
\hline \multirow[t]{2}{*}{$\begin{array}{l}\text { Mesoderm } \\
\text { (cardiogenesis) }\end{array}$} & Nkx2.5/GAPDH & $\begin{array}{c}9.831 \mathrm{E}-01 \\
(0.08)\end{array}$ & $\begin{array}{c}1.024 \mathrm{E}+00 \\
(0.08)\end{array}$ & $\begin{array}{c}1.258 \mathrm{E}+01 \\
(1)\end{array}$ & $\begin{array}{c}3.870 \mathrm{E}-01 \\
\quad(0.03)\end{array}$ \\
\hline & $\alpha-\mathrm{MHC} / \mathrm{GAPDH}$ & $\begin{array}{c}9.361 \mathrm{E}-01 \\
(0.10)\end{array}$ & $\begin{array}{c}9.323 \mathrm{E}-01 \\
(0.10)\end{array}$ & $\begin{array}{c}9.464 \mathrm{E}+00 \\
\text { (1) }\end{array}$ & $\begin{array}{c}1.463 \mathrm{E}-01 \\
(0.02)\end{array}$ \\
\hline
\end{tabular}

1, blank group; 2, empty vector control group; 3, GATA-4-overexpressing group; 4, GATA-4-silencing group.

established and maintained in $\alpha$-MEM containing $250 \mu \mathrm{g} / \mathrm{ml}$ G418. The GATA-4 protein expression was verified by Western blotting (Fig. 1), and the mRNA expression was verified by real-time RT-PCR (Fig. 2).

siRNA inhibition of GATA-4 expression. The P19 cell line which stably transfected with a GATA-4-silencing plasmid was established and maintained in $\alpha$-MEM containing $250 \mu \mathrm{g} /$ ml G418. Real-time PCR was used to identify GATA-4 (Fig. 3). Compared with the GATA-4 mRNA expression levels in the control group, those in the P19 cells that had been transfected with pGPU6-shGATA4-1491, pGPU6- 


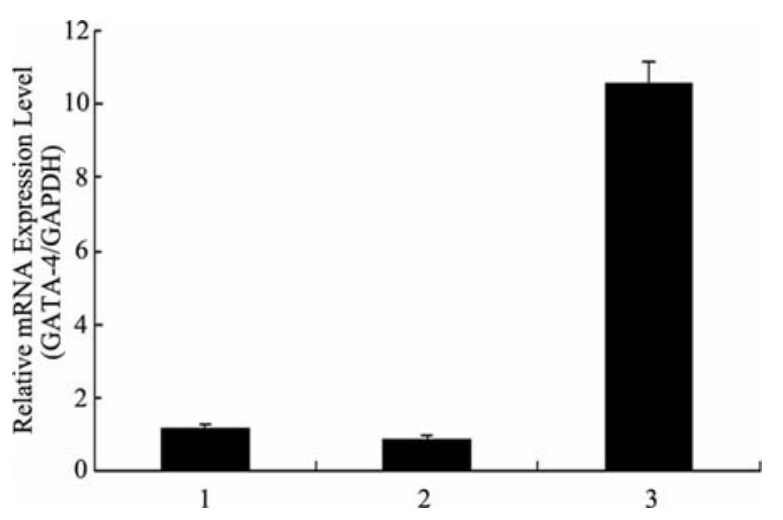

Figure 2. Expression of GATA-4 mRNA in P19 cells transfected with pcDNA3.1-GATA-4. Total RNA was isolated from stable cell lines and analyzed by qRTPCR. Lane 1, normal P19 cells; Lane 2, pcDNA3.1; Lane 3 , pcDNA3.1-GATA-4. Data were analyzed by the $2-\Delta \Delta C T$ method and normalized to GAPDH expression. ${ }^{*} \mathrm{p}<0.05 ; \mathrm{n}=4$.

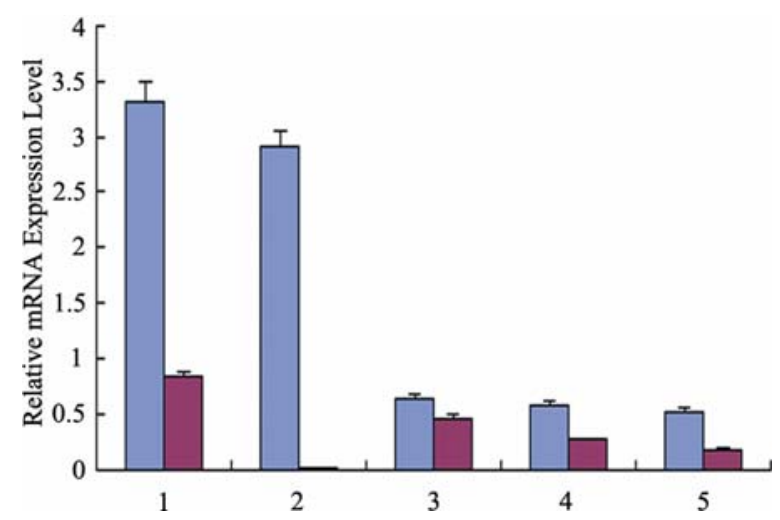

Figure 3. Expression of GATA-4 and GAPDH mRNA in P19 cells transfected with pGPU6-shGATA-4 or pGPU6-shGAPDH. Total RNA was isolated from stable cell lines and analyzed by qRT-PCR. Lane 1, pGPU6; Lane 2, pGPU6-shGAPDH; Lane 3, pGPU6-shGATA4-1491; Lane 4, pGPU6-shGATA4-1743; Lane 5, pGPU6-shGATA4-1830. " $\mathrm{p}<0.05$; n=4.

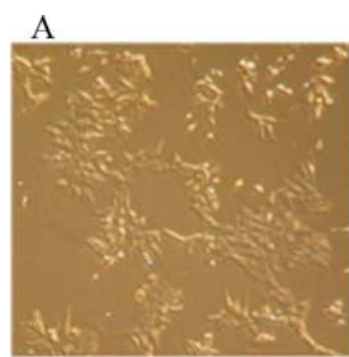

day 0 -control-1 B

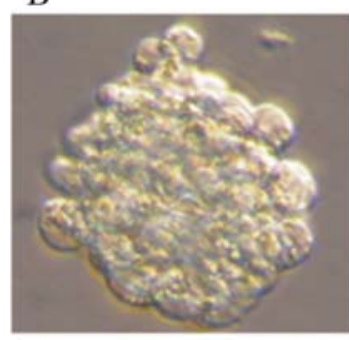

day 5-control-1 $\mathrm{C}$

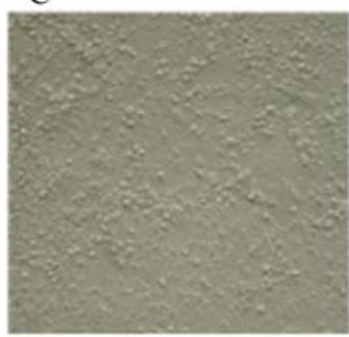

day 10 -control-1

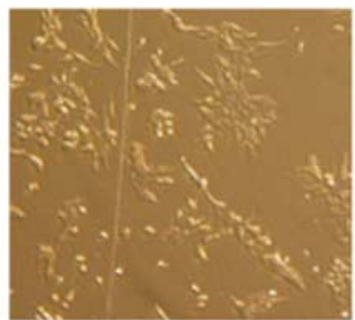

day 0 -control-2

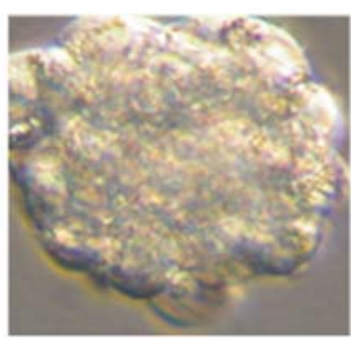

day 5-control-2

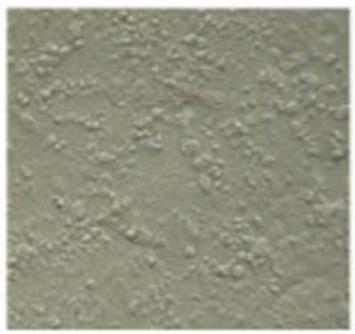

day 10 -control-2

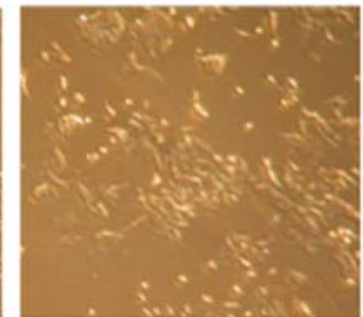

day 0 -overexpression

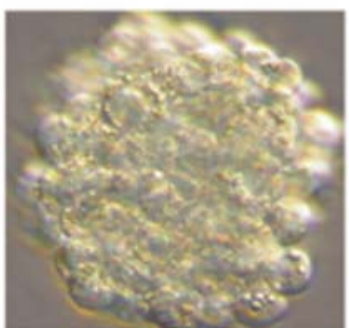

day 5-overexpression

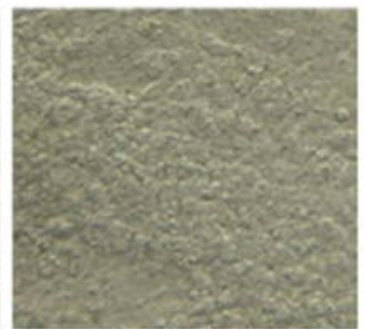

day 10-overexpression

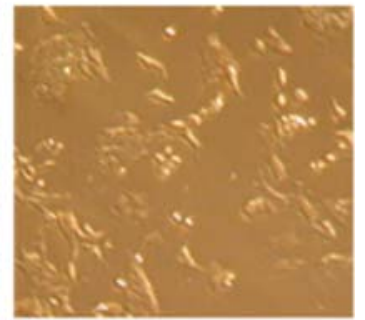

day 0 -silencing

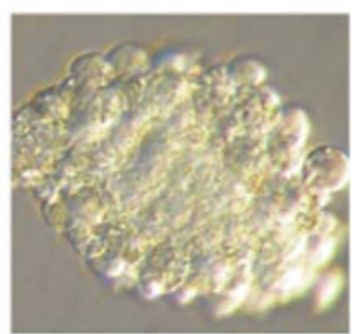

day 5 -silencing

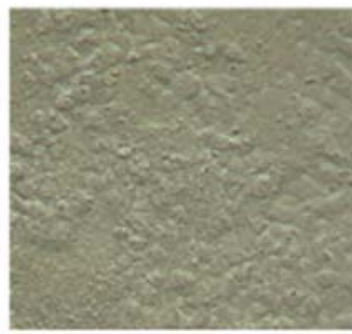

day 10 -silencing

Figure 4. Morphology of P19 cells during differentiation. Control-1, normal P19 cells; control-2, pcDNA3.1; overexpression, pcDNA3.1-GATA-4; silencing, pGPU6-shGATA4-1830.

shGATA4-1743 and pGPU6-shGATA4-1830 were 22.4, 20.4 , and $18.5 \%$, respectively.

Morphology of P19 cells during differentiation. P19 cells were derived from a pluripotent tumor in an early mouse embryo and were differentiated into various cell types depending on the environment (13). In order to investigate how P19 cells can be differentiated into cardiac cells, we examined the morphological changes in the P19 cells. The morphology of P19 cell lines with GATA-4 overexpressed or silenced on days 0,5 , and 10 of differentiation are shown (Fig. 4). The cardiac myocardial cells aggregated on day 4 of differentiation showed similar morphological changes to those observed during differentiation in all the groups. On day 10 of differentiation, the colonies of beating cells were observed more often in the overexpression group than in the 


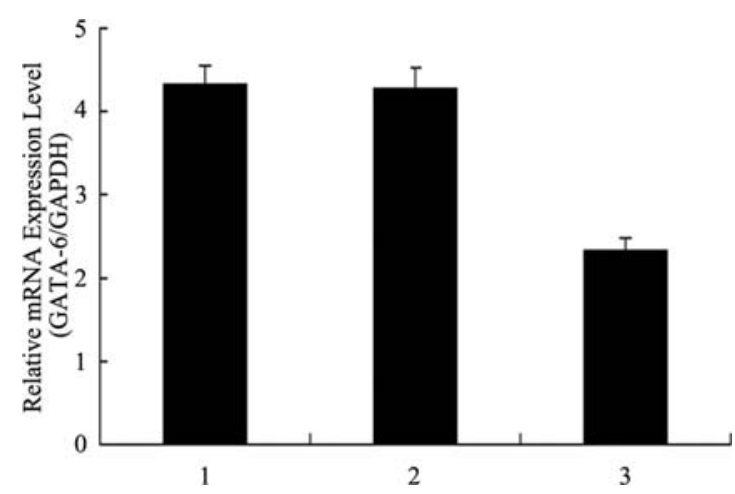

Figure 5. Expression of GATA-6 mRNA in P19 cells transfected with pcDNA3.1-GATA-4. Total RNA was isolated from stable cell lines and analyzed by qRT-PCR. Lane 1, normal P19 cell; Lane 2, pcDNA3.1; Lane 3 , pcDNA3.1-GATA-4. Data were analyzed by the $2-\Delta \Delta C T$ method and normalized to GAPDH expression. ${ }^{*} \mathrm{p}<0.05 ; \mathrm{n}=4$.

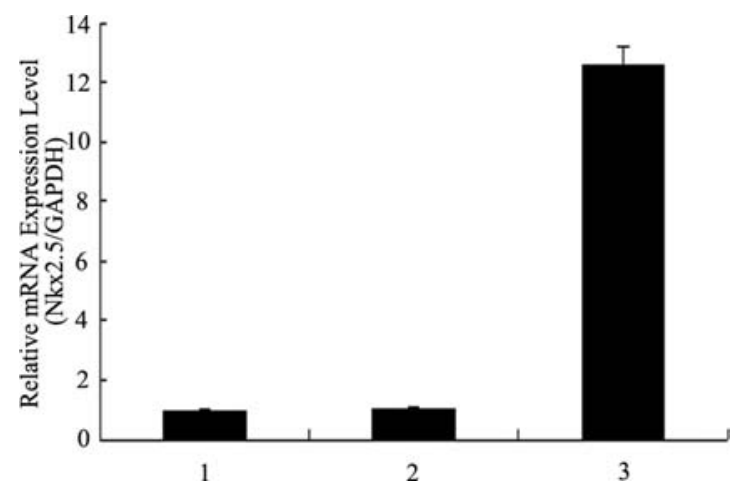

Figure 6. Expression of $N k x 2.5$ mRNA in P19 cells transfected with pcDNA3.1-GATA-4. Total RNA was isolated from stable cell lines and analyzed by qRT-PCR. Lane 1, normal P19 cells; Lane 2, pcDNA3.1; Lane 3 , pcDNA3.1-GATA-4. Data were analyzed by the $2-\Delta \Delta$ CT method and normalized to GAPDH expression. ${ }^{*} \mathrm{p}<0.05 ; \mathrm{n}=4$.

controls. However, they were hardly observed in the silenced group, indicating that GATA-4 facilitates cardiac myocyte generation.

Expression levels of marker genes in 5-day-old embryoid bodies overexpressing GATA-4. The GATA transcription factors GATA-4 and GATA- 6 are regarded as markers that are expressed in endoderm- and mesoderm-derived lineages, respectively, in embryoid bodies (EBs). TTR and AFP were used as endodermal markers that are specifically expressed in hepatocytes and the visceral endoderm of the yolk sac, respectively. The early cardiac transcription factor $N k x 2.5$ and the cardiac muscle-specific $\alpha-M H C$, were used as cardiac-specific markers (14). In this study, we used RT-PCR and analyzed the expression levels of the above-mentioned genes of 5-day-old EBs (the cells undergo a significant shift from an undifferentiated to a differentiated state during the culture of EB formation for 5 days) (14). We performed this analysis to evaluate the effects of GATA-4 on the differentiation of P19 cells into cardiac myocytes and to understand the relationship between $G A T A-4$ and cardiomyocytes. The expression level of GATA-6 was 0.5 times lower in the

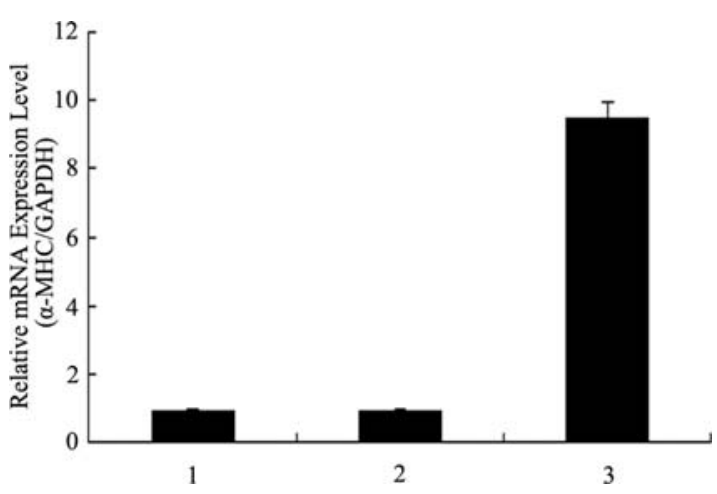

Figure 7. Expression of $\alpha-M H C$ mRNA in P19 cells transfected with pcDNA3.1-GATA-4. Total RNA was isolated from stable cell lines and analyzed by qRT-PCR. Lane 1, normal P19 cells; Lane 2, pcDNA3.1; Lane 3, pcDNA3.1-GATA-4. Data were analyzed by the 2- $\Delta \Delta \mathrm{CT}$ method and normalized to GAPDH expression. ${ }^{*} \mathrm{p}<0.05 ; \mathrm{n}=4$.

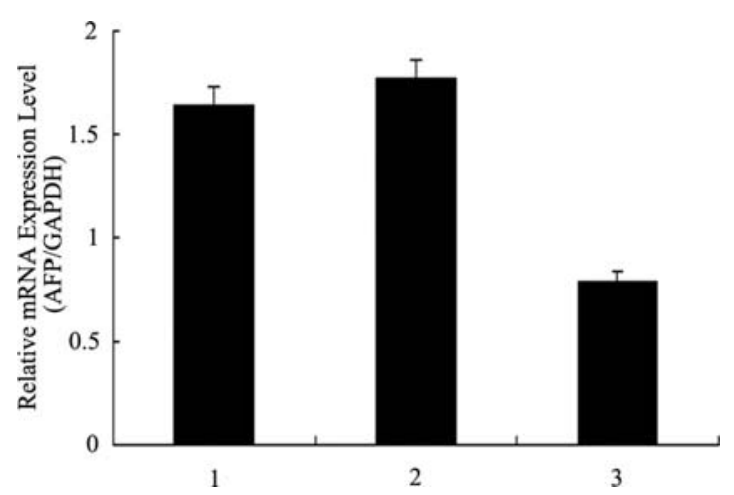

Figure 8. Expression of AFP mRNA in P19 cells transfected with pcDNA3.1-GATA-4. Total RNA was isolated from stable cell lines and analyzed by qRT-PCR. Lane 1, normal P19 cells; Lane 2, pcDNA3.1; Lane 3, pcDNA3.1-GATA-4. Data were analyzed by the $2-\Delta \Delta C T$ method and normalized to GAPDH expression. ${ }^{*} \mathrm{p}<0.05 ; \mathrm{n}=4$.

overexpression group than in the control group (Fig. 5), whereas the levels of $N k x 2.5$ (Fig. 6) and $\alpha$-MHC (Fig. 7) in the overexpression group were $\sim 12.5$ and 10 times lower, respectively, than the corresponding levels in the control group. The gene expression levels of AFP (Fig. 8) and TTR (Fig. 9) were, respectively, $\sim 0.5$ and 0.4 times lower than those in the control group.

Expression levels of marker genes in 5-day-old EBs in which the GATA-4 gene is silenced. We used real-time PCR and examined the expression levels of GATA-6, Nkx2.5, $\alpha-M H C$, $A F P$, and TTR in 5-day-old EBs to evaluate the effects of GATA-4 on the differentiation of P19 cells into cardiac myocytes. There was no significant difference between the expression levels of GATA-6 in the GATA-4-silenced cells and the control group (Fig. 10). In contrast, the levels of $N k x 2.5$ (Fig. 11) and $\alpha-M H C$ (Fig. 12) were, respectively, $\sim 0.6$ and 0.8 times lower than the corresponding levels in the control group. There was no significant difference between the expression levels of AFP in the GATA-4-silenced cells and the control group (Fig. 13), whereas the TTR (Fig. 14) level was $\sim 0.5$ times lower than that in the control group. 


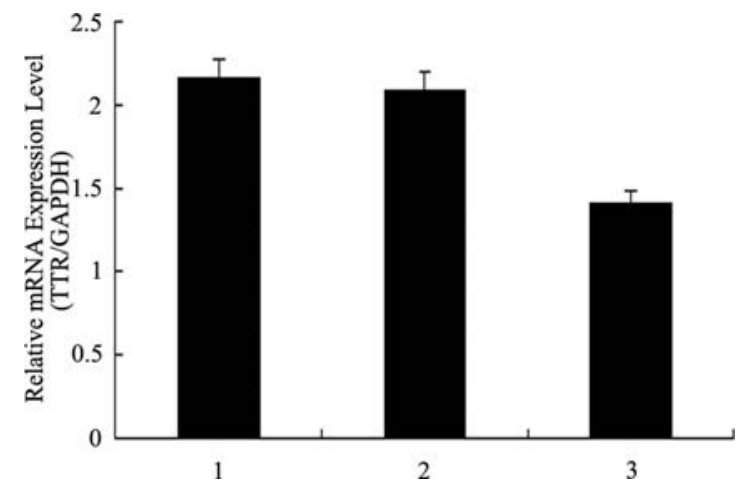

Figure 9. Expression of TTR mRNA in P19 cells transfected with pcDNA3.1-GATA-4. Total RNA was isolated from stable cell lines and analyzed by qRT-PCR. Lane 1, normal P19 cells; Lane 2, pcDNA3.1; Lane 3, pcDNA3.1-GATA-4. Data were analyzed by the $2-\Delta \Delta C T$ method and normalized to GAPDH expression. ${ }^{*} \mathrm{p}<0.05 ; \mathrm{n}=4$.

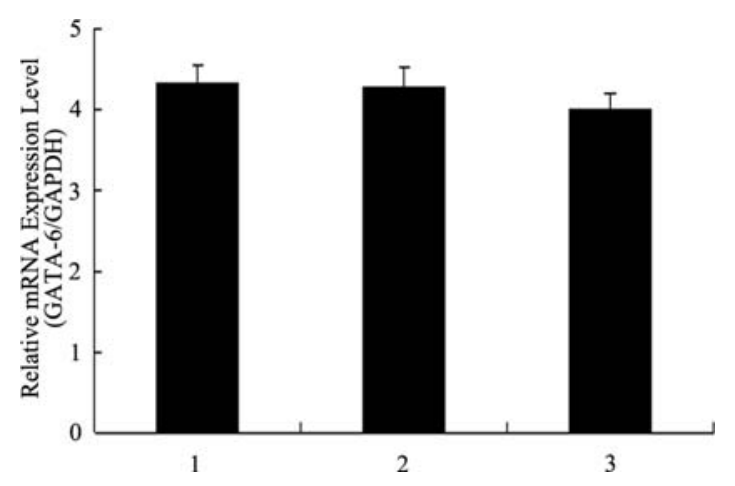

Figure 10. Expression of GATA-6 mRNA in P19 cells transfected with pGPU6-shGATA4-1830. Total RNA was isolated from stable cell lines and analyzed by qRT-PCR. Lane 1, normal P19 cells; Lane 2, P19/pGPU6; Lane 3, P19/pGPU6-shGATA4-1830. Data were analyzed by the $2-\Delta \Delta C T$ method and normalized to GAPDH expression. " $\mathrm{p}>0.05 ; \mathrm{n}=4$.

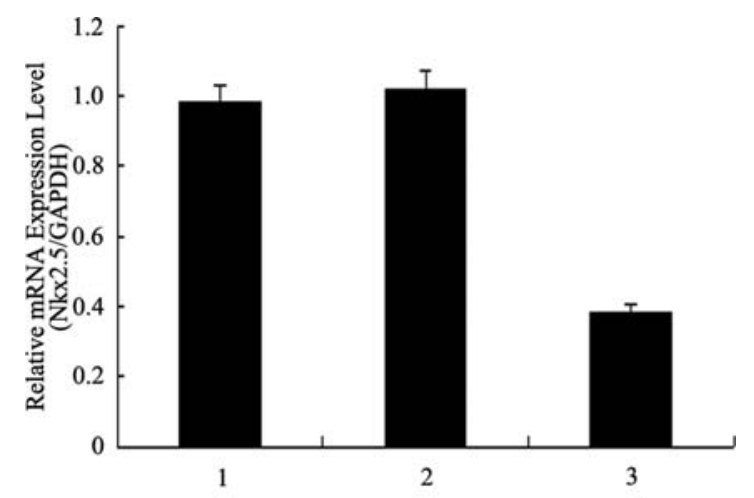

Figure 11. Expression of $N k x 2.5$ mRNA in P19 cells transfected with pGPU6-shGATA4-1830. Total RNA was isolated from stable cell lines and analyzed by qRT-PCR. Lane 1, normal P19 cells; Lane 2, P19/pGPU6; Lane 3, P19/pGPU6-shGATA4-1830. Data were analyzed by the $2-\Delta \Delta C T$ method and normalized to GAPDH expression. ${ }^{*} \mathrm{p}<0.05 ; \mathrm{n}=4$.

Characterization of the 5-day-old EBs in terms of gene expression. Table II shows the relative expression of the marker genes involved in the derivatives of the endoderm and mesoderm in 5-day-old EBs formed in different groups.

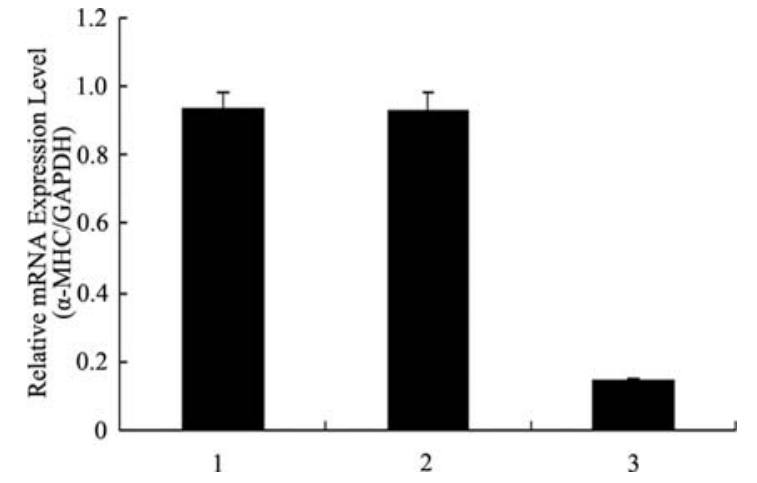

Figure 12. Expression of $\alpha-M H C$ mRNA in P19 cells transfected with pGPU6-shGATA4-1830. Total RNA was isolated from stable cell lines and analyzed by qRT-PCR. Lane 1, normal P19 cells; Lane 2, P19/pGPU6; Lane 3, P19/pGPU6-shGATA4-1830. Data were analyzed by the $2-\Delta \Delta C T$ method and normalized to GAPDH expression. ${ }^{*} \mathrm{p}<0.05 ; \mathrm{n}=4$.

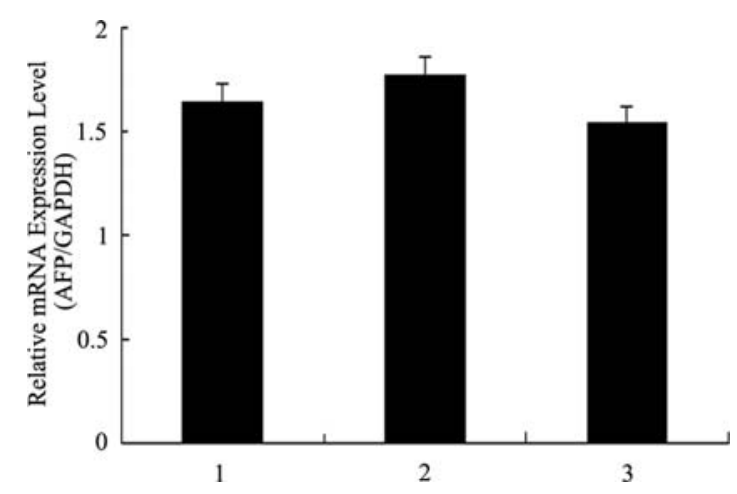

Figure 13. Expression of AFP mRNA in P19 cells transfected with pGPU6shGATA4-1830. Total RNA was isolated from stable cell lines and analyzed by qRT-PCR. Lane 1, normal P19 cells; Lane 2, P19/pGPU6; Lane 3, P19/pGPU6-shGATA4-1830. Data were analyzed by the $2-\Delta \Delta C T$ method and normalized to GAPDH expression. ${ }^{*} \mathrm{p}>0.05 ; \mathrm{n}=4$.

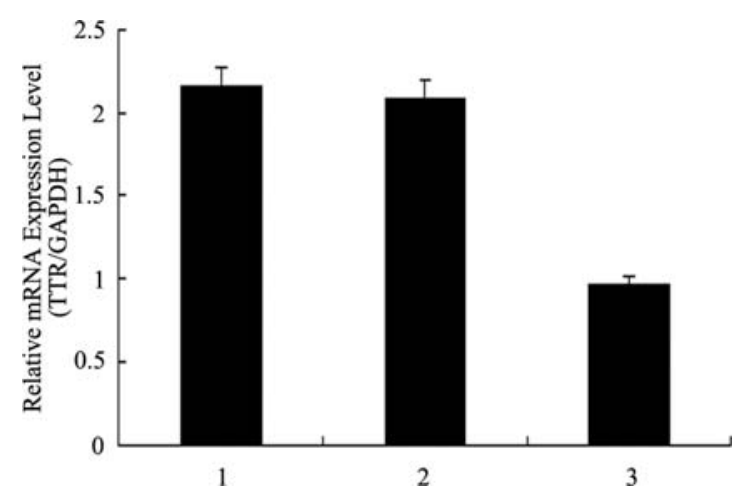

Figure 14. Expression of TTR mRNA in P19 cells transfected with pGPU6shGATA4-1830. Total RNA was isolated from stable cell lines and analyzed by qRT-PCR. Lane 1, normal P19 cells; Lane 2, P19/pGPU6; Lane 3, P19/pGPU6-shGATA4-1830. Data were analyzed by the $2-\Delta \Delta C T$ method and normalized to GAPDH expression. ${ }^{*} \mathrm{p}<0.05 ; \mathrm{n}=4$.

The characterization of the EBs in terms of relative gene expression was represented by the ratios to the highest level in each marker gene. The ratios of gene expression levels, shown within parentheses in Table II, were plotted on 6 

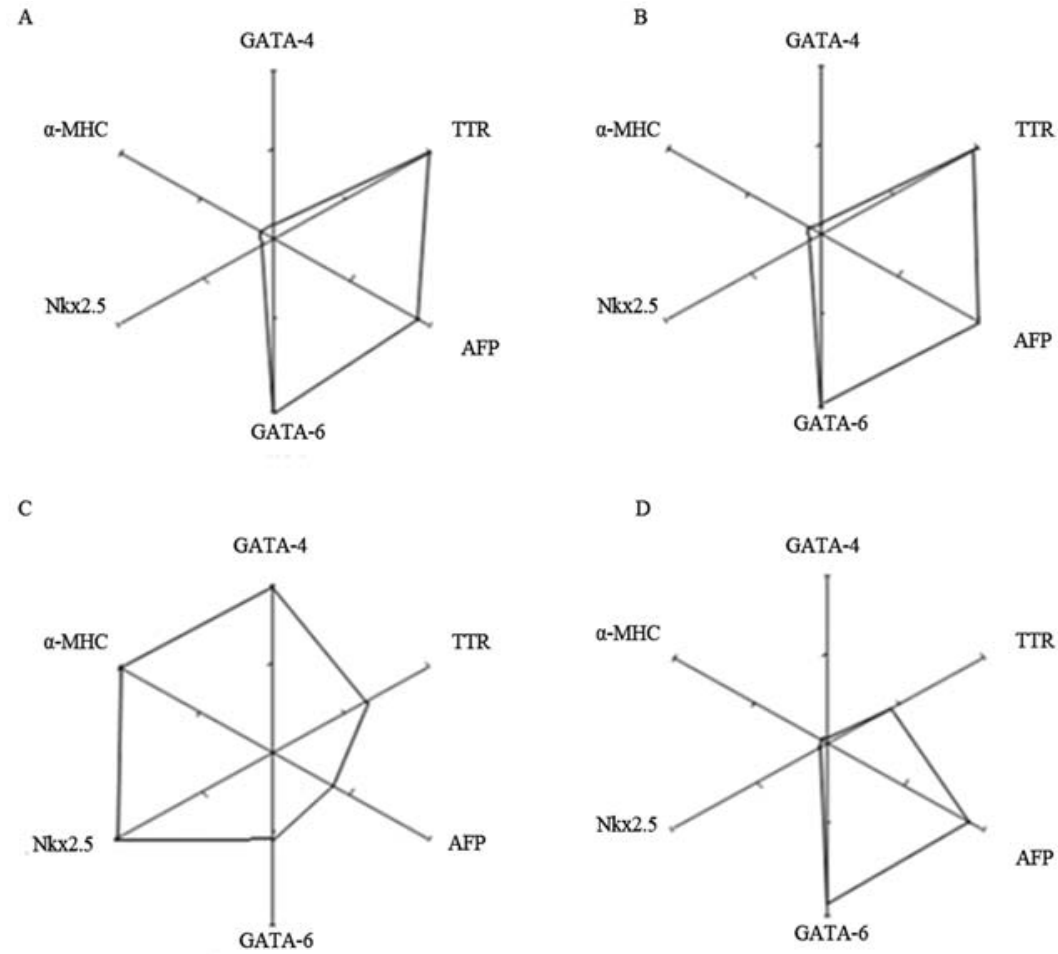

Figure 15. Charts of gene expression pattern in 5-day-old embryoid bodies formed in different groups. (A) Blank group; (B) empty vector control group; (C) GATA-4-overexpressing group; (D) GATA-4-silenced group. Original data are shown in Table II.

radial axes (Fig. 15). The ratios of the expression levels of GATA-4 and GATA-6 were plotted on the upper and lower vertical axes, respectively. The ratios of the expression levels of $N k x 2.5$ and $\alpha-M H C$ were plotted on 2 axes on the left side, and the ratios of TTR and AFP were plotted on 2 axes on the right side. By connecting the plots on all the axes, an enclosed area appeared on the chart. This enclosed area defined the gene expression pattern that characterizes the differentiation status of the EBs.

The gene expression pattern in the EBs of the GATA-4overexpressing group was biased toward the left side of the chart involving $N k \times 2.5$ and $\alpha-M H C$. In contrast, the gene expression pattern in the EBs of the GATA-4-silenced group was similar to that in the control group. However, the enclosed area on the left side of the GATA-4-silenced group was smaller than the one on the right side, compared to the control group.

\section{Discussion}

Cardiogenesis involves a series of processes involving multiple cell line specialization, tubular structure formation, and precise assembly into the mature 4-chamber cardiac structure. This process entails a series of important events, including cell determination, migration, and differentiation. At the cellular level, it involves cell temporospatial differentiation, migration, proliferation and apoptosis. At the molecular level, a number of signal transduction pathways regulate the process of heart development $(15,16)$. GATA transcription factors are zinc-finger DNA-binding proteins that regulate diverse pathways associated with embryonic morphogenesis and cellular differentiation (2). GATA-4 was initially described as an early cardiogenic marker, although the first requirement of mammalian GATA-4 occurs within the extra-embryonic visceral endoderm for embryonic morphogenesis $(6,17)$. On the basis of its expression in the early precardiac mesoderm and the phenotypes resulting from the various gain- and loss-of-function experiments, GATA-4 is considered to be a key regulator of cardiogenesis (18). However, some other researchers believe that GATA-4deficient embryonic stem cells retain the ability to differentiate into cardiomyocytes in vitro, and an analysis of cells from chimeric GATA-4-knockout mice has proven that GATA-4 is not required for cardiomyocyte differentiation (19). Recent findings suggest that GATA-4 can determine the fates of endoderms and facilitate, with temporal and spatial specificity, the generation of cardiomyocyte progenitors from the associated mesoderm (20). Further study is required in order to fully understand the relationship between GATA-4 and cardiac myocytes.

DMSO is known to induce the differentiation of pluripotent P19 cells into embryonic myocardial cells. P19 cells are a useful model system for investigating the roles of various factors in cardiac induction and differentiation (12). P19 cells also represent an excellent model system for studying the regulation of myocardial electrophysiological differentiation at the molecular and functional levels (21). In the present study, the expression of $N k x 2.5$ and $\alpha-M H C$ was up-regulated in the cell lines overexpressing GATA-4 and down-regulated in those in which GATA-4 was silenced. The early cardiac transcription factor $N k x 2.5$ and the cardiac muscle-specific $\alpha-M H C$ are specific cardiac markers. Therefore, we believe that the overexpression of GATA-4 enhances the differentiation of P19 cells into cardiac myo- 
cytes and suppresses the differentiation of P19 cells into the cells generated from the endoderm.

$N k \times 2.5$ is one of the early indicators of embryonic development (22). The transfection of $N k x 2.5$ into zebrafish fibroblast cells can induce the expression of the markers of cardiac myocyte differentiation; this suggests that noncardiac cells overexpressing $N k x 2.5$ can also be used to observe the process of heart differentiation (23). There is further evidence that $N k x 2.5$ plays an important role in the differentiation of P19 cells into myocardial cells (24). In this study, the overexpression of GATA-4 significantly increased the expression of $N k \times 2.5$ and therefore, we believe that GATA-4 promotes the differentiation of P19 cells into cardiac myocytes. $\alpha-M H C$ (increased by the overexpression of GATA-4 in this study) has been confirmed to be mainly expressed as a downstream target of GATA-4 in the myocardium (25).

This study also showed that the overexpression of GATA-4 downregulates the expression levels of AFP, GATA- 6 and $T T R$, suggesting that GATA-4 can suppress the differentiation of P19 cells into the cells generated from the endoderm. The inhibition of GATA-4 also downregulates the expression level of TTR. However, from the chart of gene expression patterns, the enclosed area on the left side of the GATA-4-silenced group was smaller than the one on the right side, compared to the control group. Thus, we believe that the inhibition of GATA-4 suppresses the differentiation of $\mathrm{P} 19$ cells into cardiac myocytes. Consistent with the various gain- and loss-offunction experiments, GATA-4 is considered a key regulator of cardiogenesis.

In conclusion, we believe that overexpression of GATA-4 enhances the trend of P19 cell differentiation into cardiac myocytes, whereas the downregulation of GATA-4 suppresses this trend. Further study of the function of GATA-4 and the analysis of the relationship between GATA-4 and cardiogenesis, may help to clarify the pathophysiological mechanisms of congenital heart disease and aid in improving diagnosis as well as in developing novel therapeutic strategies.

\section{Acknowledgements}

This study was supported by a grant from the Natural Science Foundation of Jiangsu Province, China (no. BK2004156).

\section{References}

1. Gittenberger-de Groot AC, Bartelings MM, Deruiter MC and Poelmann RE: Basics of cardiac development for the understanding of congenital heart malformations. Pediatr Res 57: 169-176, 2005.

2. Patient RK and McGhee JD: The GATA family (vertebrates and invertebrates). Curr Opin Genet Dev 12: 416-422, 2002.

3. Orkin SH: GATA-binding transcription factors in hematopoietic cells. Blood 80: 575-581, 1992.

4. Grepin C, Dagnino L, Robitaille L, Haberstroh L, Antakly T and Nemer M: A hormone-encoding gene identifies a pathway for cardiac but not skeletal muscle gene transcription. Mol Cell Biol 14: 3115-3129, 1994.

5. Heikinheimo M, Scandrett JM and Wilson DB: Localization of transcription factor GATA-4 to regions of the mouse embryo involved in cardiac development. Dev Biol 164: 361-373, 1994.
6. Kuo CT, Morrisey EE, Anandappa R, Sigrist K, Lu MM, Parmacek M S, Soudais C and Leiden JM: GATA4 transcription factor is required for ventral morphogenesis and heart tube formation. Genes Dev 11: 1048-1060, 1997.

7. Molkentin JD, Lin Q, Duncan SA and Olson EN: Requirement of the transcription factor GATA4 for heart tube formation and ventral morphogenesis. Genes Dev 11: 1061-1072, 1997.

8. Garg V, Kathiriya IS, Barnes R, Schluterman MK, King IN, Butler CA, Rothrock CR, Eapen RS, Hirayama-Yamada K, Joo K, Matsuoka R, Cohen JC and Srivastava D: GATA4 mutations cause human congenital heart defects and reveal an interaction with TBX5. Nature 424: 443-447, 2003.

9. Rajagopal SK, Ma Q, Obler D, Shen J, Manichaikul A, TomitaMitchell A, Boardman K, Briggs C, Garg V, Srivastava D, Goldmuntz E, Broman KW, Benson DW, Smoot LB and Pu WT: Spectrum of heart disease associated with murine and human GATA4 mutation. J Mol Cell Cardiol 43: 677-685, 2007.

10. Pu WT, Ishiwata T, Juraszek AL, Ma Q and Izumo S: GATA4 is a dosage-sensitive regulator of cardiac morphogenesis. Dev Biol 275: 235-244, 2004.

11. Zeisberg EM, Ma Q, Juraszek AL, Moses K, Schwartz RJ, Izumo $\mathrm{S}$ and $\mathrm{Pu}$ WT: Morphogenesis of the right ventricle requires myocardial expression of Gata4. J Clin Invest 115: 1522-1531, 2005.

12. Van der Heyden MA and Defize LH: Twenty one years of P19 cells: what an embryonal carcinoma cell line taught us about cardiomyocyte differentiation. Cardiovasc Res 58: 292-302, 2003.

13. McBurney MW, Jones-Villeneuve EM, Edwards MK and Anderson PJ: Control of muscle and neuronal differentiation in a cultured embryonal carcinoma cell line. Nature 299: 165-167, 1982.

14. Koike M, Sakaki S, Amano Y and Kurosawa H: Characterization of embryoid bodies of mouse embryonic stem cells formed under various culture conditions and estimation of differentiation status of such bodies. J Biosci Bioeng 104: 294-299, 2007.

15. Olson EN: Gene regulatory networks in the evolution and development of the heart. Science 313: 1922-1927, 2006.

16. Clark KL, Yutzey KE and Benson DW: Transcription factors and congenital heart defects. Annu Rev Physiol 68: 97-121, 2006.

17. Narita N, Bielinska M and Wilson DB: Wild-type endoderm abrogates the ventral developmental defects associated with GATA-4 deficiency in the mouse. Dev Biol 189: 270-274, 1997.

18. Pikkarainen S, Tokola H, Kerkela R and Ruskoaho H: GATA transcription factors in the developing and adult heart. Cardiovasc Res 63: 196-207, 2004.

19. Narita N, Bielinska M and Wilson DB: Cardiomyocyte differentiation by GATA-4-deficient embryonic stem cells. Development 124: 3755-3764, 1997.

20. Holtzinger A, Rosenfeld GE and Evans T: Gata4 directs development of cardiac-inducing endoderm from ES cells. Dev Biol 337: 63-73, 2010.

21. Van der Heyden MA, van Kempen MJ, Tsuji Y, Rook MB, Jongsma HJ and Opthof T: P19 embryonal carcinoma cells: a suitable model system for cardiac electrophysiological differentiation at the molecular and functional level. Cardiovasc Res 58: 410-422, 2003.

22. Schott JJ, Benson DW, Basson CT, Pease W, Silberbach GM, Moak J P, Maron BJ, Seidman CE and Seidman JG: Congenital heart disease caused by mutations in the transcription factor NKX2-5. Science 281: 108-111, 1998.

23. Cleaver OB, Patterson KD and Krieg PA: Overexpression of the tinman-related genes XNkx-2.5 and XNkx-2.3 in Xenopus embryos results in myocardial hyperplasia. Development 122 : 3549-3556, 1996.

24. Jamali M, Rogerson PJ, Wilton S and Skerjanc IS: Nkx2-5 activity is essential for cardiomyogenesis. J Biol Chem 276: 42252-42258, 2001.

25. Wright CE, Haddad F, Qin AX, Bodell PW and Baldwin KM: In vivo regulation of beta-MHC gene in rodent heart: role of $\mathrm{T} 3$ and evidence for an upstream enhancer. Am J Physiol 276: C883-C891, 1999. 